\title{
APRESENTAÇÃo
}

\section{Redistribuição ou reconhecimento, 15 anos depois}

Paulo Sérgio Costa Neves' Luiz Gustavo da Cunha de Souza ${ }^{2}$

O debate entre Nancy Fraser e Axel Honneth marcou época no âmbito da filosofia e das ciências sociais entre fins dos anos 1990 e início dos 2000. O dossiê aqui reunido, agregando perspectivas variadas e celebrando criticamente os 15 anos do debate, busca mostrar o quanto essa discussão é ainda atual e passível de iluminar aspectos importantes da sociedade brasileira contemporânea. Para isso, o dossiê reúne textos de autoras e autores do país que, ao longo desta década e meia, de algum modo se apropriaram das categorias de redistribuiçáo e reconhecimento como utilizadas por Fraser e Honneth, mas ao mesmo tempo buscaram traduzi-las de modo a possibilitar um melhor entendimento da realidade brasileira. Além disso, o dossiê conta ainda com a tradução de um texto original de Fraser e outro de Honneth.

Como se sabe, o livro Redistribution or Recognition: A PoliticalPhilosophical Exchange (FRASER; HONNETH, 2003), publicado simultaneamente em inglês e alemão em 2003, com textos de Nancy Fraser e

\footnotetext{
Doutor em sociologia e ciências sociais pela Université Lumiere Lyon 2 e professor titular da Universidade Federal do ABC. Contato: pscneves@hotmail.com.

2 Doutor em sociologia pela Universidade Estadual de Campinas (Unicamp) e professor de Sociologia na Universidade Federal de Santa Catarina (UFSC). Contato: gustavo.cunha.s@ufsc.br.
}

\section{$(\mathrm{cc}) \mathrm{Br}$}

Direito autoral e licença de uso: Este artigo está licenciado sob uma Licença Creative Commons. Com essa licença você pode compartilhar, adaptar, para qualquer fim, desde que atribua a autoria da obra, forneça um link para a licença, e indicar se foram feitas alterações. 
Axel Honneth, embora seja o ponto culminante desse debate, não marca nem seu início, nem seu fim, uma vez que esses prolíficos autores continuaram a desenvolver suas obras em diálogo se não diretamente, de forma intermediada e responsiva às críticas e réplicas que marcaram as trocas de ideias entre eles.

$\mathrm{Na}$ verdade, o conceito-chave aqui é o de reconhecimento, o qual, ao mesmo tempo em que encanta por seu poder explicativo e por sua dimensão potencialmente emancipatória, também nos questiona, por conta de seu possível uso para legitimar injustiças em nome da defesa de especificidades culturais e identitárias.

Quando, nos anos 1980 e início dos anos 1990, autores como Charles Taylor (1989, 1992), Iris Marion Young (1990), Axel Honneth (1992), dentre outros, passam a usar o conceito de reconhecimento tanto para dar conta das demandas multiculturais de grupos minoritários na sociedade quanto para formular teorias da justiça social, os modos hegemônicos de definiçãao da justiça e da vida boa se modificam. Se até então o modelo forjado por Rawls (1972), assentado em uma perspectiva majoritariamente redistributiva, era, apesar de muito criticado por autores tão diversos quanto Habermas (HABERMAS; RAWLS, 1997), Roemer (1996) e os chamados comunitaristas (MACINTYRE, 1981; SANDEL, 1982, WALZER, 1983), a versão mais em voga, naquele momento, as perspectivas teórico-normativas voltadas para o reconhecimento passaram a ocupar, no mínimo, um espaço tão grande quanto as redistributivas.

De fato, o debate sobre redistribuição ou reconhecimento se insere na discussão mais ampla sobre a crise da sociedade do trabalho e a emergência de um novo paradigma do conflito social, marcado pela ascensão dos chamados novos movimentos sociais, conforme analisados por uma série de autores como Alain Touraine, André Gorz ou o próprio Habermas (OFFE, 1989). É nesse contexto que emergem ou ganham mais destaque, já nas décadas de 1960 e 1970, aqueles movimentos que, de modo geral, se poderia associar às lutas por identidade. Se do ponto de vista político a entrada em cena de tais movimentos representou uma mudança radical das concepçóes e formas da representação política - e isso gerou efeitos tanto sobre as posiçóes políticas progressistas quanto sobre aquelas conservadoras - do ponto de vista da teoria social o efeito foi táo grande quanto, já que à dita 
crise da integração pelo trabalho e à emergência do paradigma alternativo da identidade e do mundo vida corresponderam também a formulação de teorias filosóficas e sociais a respeito do reconhecimento.

Nesse sentido, o livro de Honneth, Luta por Reconhecimento, cuja primeira edição em alemão é de 1992, transformou-se na ponta de lança para as teorias do reconhecimento, tornando-se rapidamente o texto de maior sucesso sobre o tema nesse período. Assim, é natural que os críticos à emergência do reconhecimento como principal critério de justiça direcionassem sua crítica a Honneth, que se tornou assim, a contragosto, o porta-voz da corrente que punha o reconhecimento no centro do debate. Como mencionado, porém, essa é uma posição conquistada a contragosto, pois o próprio Honneth repetidas vezes procurou se afastar da posiçáo comunitarista, insistindo que sua teoria do reconhecimento é antes um modelo normativo de análise do social - conforme evidencia Deranty (2009), especialmente no capítulo 11 de seu livro. Nesse sentido, em seu entendimento, o conceito de reconhecimento dialoga tanto com as lutas identitárias do presente quanto com a ampla tradição de teorias críticas da sociedade.

Torna-se claro, pois, que esse debate é mais amplo e engloba mais vertentes que as representadas pelos dois autores que aqui servem de mote: por um lado, a intenção fundamental de atualizar diagnósticos críticos sobre as sociedades contemporâneas e seus conflitos sociais faz com que a formulação de um novo quadro analítico se faça em diálogo com as principais teorias da justiça e da sociedade capitalista vigentes naquela época; por outro lado, essa crítica ao entáo estado da arte da teoria demanda a apreensão (sociológica, poder-se-ia dizer) da nova feição social. Assim, as discussóes sobre justiça, nos anos 1990, trazem a marca da crítica aos modelos pautados apenas na repartição dos bens materiais (marxismo, Rawls etc.), o que já vinha sendo debatido pelos autores ditos comunitaristas desde o final dos anos 1980. Contudo, essa crítica vai ganhar um novo élan justamente a partir das discussóes sobre o conceito do reconhecimento que autores como Taylor e Honneth vão propor, ou de conceitos correlatos como diferença e multiculturalismo (YOUNG, 1990; KYMLICKA, 1995).

Por trás dessa emergência conceitual havia certamente uma influência das mobilizaçóes de grupos que reivindicavam cada vez mais o direito à diferença e ao reconhecimento (mulheres, negros, gays, imigrantes etc.) 
em sociedades cada vez mais diversas e moldadas por correntes migratórias importantes. Ora, na medida em que a hegemonia de um paradigma de lutas sociais e análises socioteóricas desloca o lugar antes ocupado pelo outro paradigma, a pergunta a ser feita é: qual a relação existente entre ambos os paradigmas? Mais ainda: se a crítica de autores como Honneth e Taylor à tradição da teoria da justiça incluí as lutas identitárias, mas quer ver no reconhecimento algo mais do que isso, como acomodar a influência das demandas pelo direito à diferença com as demandas universalistas? Finalmente: como esses modelos de mobilização política e formulação teórica podem sustentar uma crítica das sociedades presentes, conforme esses autores pretendem?

Nesse sentido, a importância da crítica de Fraser aos autores que defendiam a bandeira do reconhecimento tem o mérito de que, ao mesmo tempo em que admitia a importância do conceito para as lutas sociais e para uma dimensão heurística da justiça, trazia à tona, também, a importância de não abandonar os autores redistributivistas e, por isso mesmo, notava os riscos de uma política de reconhecimento que fechasse os olhos para as tradicionais - e ainda não superadas - questóes redistributivas. Daí que, para Fraser, o conceito de reconhecimento está, sim, no centro do debate, mas sua ausência não pode ser o único motivo de crítica social, devendo acompanhar a ausência de redistribuição.

Essa busca de síntese será criticada por Honneth ou Young, por exemplo, que vêm nesse retorno da autora à visão dualista da vida social a incapacidade de perceber que, nas demandas por reconhecimento, as demandas redistributivas estavam embutidas; dessa forma, seria necessário antes um conceito mais sofisticado de reconhecimento do que um melhor diagnóstico das relaçôes entre redistribuição e reconhecimento. Por outro lado, o "monismo normativo" dos defensores do reconhecimento parecerá a Fraser redutivista na medida em que demandas por reconhecimento acabam por transferir do espaço social para o espaço psicológico o impulso vivenciado como sentimento de injustiça.

Seja como for, o livro debate de 2003 é o momento maior da oposição entre a defesa do reconhecimento como conceito síntese de uma perspectiva ampliada de justiça e a crítica a essa posição, insistindo na importância das demandas materiais que, acopladas às demandas por reconhecimento, seriam as marcas de uma teoria da justiça capaz de dar conta dos desafios 
nas sociedades contemporâneas a partir de uma perspectiva dualista. Adicionalmente, tanto Fraser quanto Honneth defendem que suas respectivas posiçóes no debate são alternativas para a formulação - ou reconstrução - de uma Teoria Crítica do presente, reivindicando, com isso, a herança daqueles modelos de crítica política do presente que se iniciam em Marx e seus contemporâneos do hegelianismo de esquerda e se autonomizam como corrente do pensamento social na tradição da Escola de Frankfurt. Assim, Fraser e Honneth propunham também realizar um balanço do debate sobre os dois conceitos de redistribuição e reconhecimento a partir de seus próprios aportes sobre como deveria se portar em relação a eles uma teoria crítica da sociedade. O livro, então, não abre um debate, pelo contrário: Fraser e Honneth sumarizam e organizam a forma como a Teoria Crítica poderia lidar com um debate que já vinha ocorrendo nas ciências humanas e sociais e na filosofia há algumas décadas e, a partir disso, desdobram seus modelos de crítica do presente, de suas lutas e disputas.

Esse debate entre os dois inicia-se, de fato, no final dos anos 1990, quando Fraser publica uma série de artigos (1997) defendendo a posição crítica aos autores que fundamentavam suas teorias no conceito do reconhecimento e da diferença. Em resposta a essas críticas, Honneth constantemente defendeu a ideia de que seu conceito de reconhecimento não deveria ser lido como uma defesa da diferença como identidade, mas sim como um processo formativo da personalidade individual. A isso, por sua vez, Fraser replicava afirmando que nesse movimento perdia-se a relaçáo entre a crítica social e os paradigmas de justiça mobilizados pelos próprios membros da sociedade, ao que Honneth, por fim, treplicava defendendo que o ponto de apoio normativo da crítica não se expressa no discurso público a respeito da injustiça, mas sim na experiência prévia e intuitiva de sentir-se vítima de uma injustiça. O livro de 2003 é, pois, uma consequência desse debate que envolveu Nancy Fraser e Axel Honneth, mas não é apenas isso, como vimos.

No Brasil, esse debate reverberará muito cedo, tendo gerado uma série de artigos e livros sobre o tema desde o início dos anos 2000. Em que pese a diferença dos contextos nos quais foram produzidas as teorias de Fraser e Honneth para a realidade brasileira, ao menos duas grandes correntes de interlocução com seu modelos podem ser identificadas no Brasil. Por um lado, aquelas autoras e autores que se dedicaram à discussão das categorias 
de redistribuição e reconhecimento à luz de teorias críticas ou da justiça e trabalharam tanto nas disciplinas específicas das ciências sociais como como a sociologia ou a ciência política, quanto em termos mais amplos em diálogo com a filosofia (MATTOS, 2006; MELO, 2013; SAAVEDRA; SOBOTTKA, 2009; SILVA, 2008). Por outro lado, numerosas pesquisadoras e numerosos pesquisadores tomaram a apropriação e tradução das categorias mobilizadas no debate entre Fraser e Honneth como seu ponto de partida para a análise de lutas sociais na forma como ocorriam no contexto brasileiro, propiciando análises particularmente frutíferas a respeito de movimentos sociais e do mercado de trabalho no Brasil (JARDIM, 2016; NEVES, 2005, 2007; PAIVA, 2015; ROSENFIELD; SAAVEDRA, 2013; ROSENFIELD; MELLO; CORRÊA, 2015; SILVA, 2017). Os textos aqui reunidos, então, tentam mostrar o quanto esse debate ainda incita a imaginação de nossos pesquisadores para pensar novas pistas de pesquisas e novos diálogos teóricos, o que demonstra a vitalidade e a pertinência da discussão entre os defensores do reconhecimento e da redistribuição para pensar o justo em nosso tempo e em nosso país.

Para coroar essa discussão e demonstrar o quanto o debate marcou a obra dos dois autores dos quais nos ocupamos aqui, ambos aceitaram participar desse dossiê, autorizando a publicação em português de textos anteriormente publicados originalmente em inglês, no caso de Fraser, e em alemão, no caso de Honneth. Ao contrário do livro de 2003, porém, optamos por inverter a ordem do debate e iniciar o dossiê com o já clássico texto, publicado por Honneth inicialmente em 1993 "A dinâmica social do desrespeito" (HONNETH, 2000). Essa opção parece justificada porque é nesse artigo, originalmente apresentado como uma palestra, que Honneth apresenta de modo condensado o desenvolvimento do conceito de reconhecimento que fora exposto em Luta por reconhecimento. Todavia, esse artigo é mais do que um resumo da tese, pois nele o autor repassa suas dúvidas quanto ao projeto mesmo de uma Teoria Crítica da sociedade conforme elaborado por Max Horkheimer na década de 1930, assim como expóe aquilo que considera serem os limites da reformulação efetuada por Habermas à Teoria Crítica, de modo que é nesse texto que a linha evolutiva do pensamento honnethiano até a construção do conceito de reconhecimento aparece com mais clareza. Por fim, na medida em que se trata de um texto programático, nele Honneth ainda aponta para alguns possíveis 
desenvolvimentos da teoria do reconhecimento que, mais tarde, seriam centrais náo apenas para seu debate com Fraser, mas para toda a compreensão do reconhecimento que se dá ao redor de sua obra.

Já o texto traduzido de Fraser, pelo contrário, (ainda) não é um clássico, mas um artigo recente, no qual a autora passa em revista a falência da aliança entre políticas liberais de reconhecimento e modelos econômicos neoliberais (FRASER, 2017). O interesse inicial desse artigo parece se dirigir a um diagnóstico político, inclusive devido à menção à eleição de Donald Trump para a presidência dos Estados Unidos já no título, mas essa é uma falsa impressão: ainda que exista, a dimensão diagnóstica serve aqui antes à crítica da domesticação do potencial crítico das lutas políticas, já que o tipo de progressismo que se tornara aceitável por meio das lutas por reconhecimento era, de acordo com Fraser, muito menos disposto a propor mudanças radicais nas relaçóes políticas e, em especial, na economia. Desse modo, à crítica feita ao reconhecimento por ocasião do debate com Honneth, Fraser acrescenta aqui outro elemento, ao qual já parecia aludir em 2003: os efeitos políticos das lutas por reconhecimento, que lá apareciam como uma possível terceira dimensão da justiça, a da participação, aqui aparecem como a construção de um paradigma populista progressista que seja capaz de incluir diferentes grupos e demandas por voz ativa dentro da sociedade, ao mesmo tempo em que propóe uma alternativa ao sistema econômico neoliberal. Nesse sentido, no texto traduzido nesse dossiê, é possível notar vários desdobramentos de seu trabalho desde o debate com Honneth.

Com a tradução desses dois artigos, então, pretendemos oferecer às leitoras e aos leitores de Politica \& Sociedade a oportunidade de observarem como o debate sobre redistribuição ou reconhecimento, assim como as obras de Fraser e Honneth, se desdobram em várias outras direções além do livro que marca seu ponto culminante. E é de alguns desses desdobramentos que os textos de acadêmicas brasileiras e acadêmicos brasileiros aqui reunidos buscam dar conta. Passamos, pois, às apresentaçóes dos demais textos deste dossiê.

Juntamente com os textos de Honneth e Fraser, o texto de Emil Sobottka e Thais de Santo compóe aquilo que poderia ser visto como uma primeira sessão do dossiê, na qual os conceitos de redistribuição, reconhecimento e justiça são tratados mais formalmente. Iniciando com uma 
referência à tradição de debates conceituais públicos, algo particularmente importante nas ciências sociais, o artigo de Sobottka e de Santo, chamado "Reconhecimento, justiça e a questão da autonomia: desafios para uma teoria social normativa”, toma seu ponto de partida na controvérsia aberta por Fraser ao associar a emergência do conceito de reconhecimento com o diagnóstico de uma era pós-socialista. Segundo os autores, enquanto para Honneth a construção da teoria do reconhecimento se desdobraria como uma série de passos teóricos em que intuiçôes específicas - advindas da teoria social e da análise de práticas e rotinas dos indivíduos - seriam testadas como elementos de crítica de modelos teóricos anteriores, Fraser tomaria essa categoria analítica como referente às questóes de identidade e, por isso, proporia uma teoria dual da justiça, na qual redistribuição e reconhecimento seriam paradigmas da justiça. Assim, Sobottka e de Santo oferecem um balanço da crítica de Fraser e da resposta de Honneth, chamando a atenção tanto para a ênfase dada por ela à dimensão da redistribuição material quanto para um certo "déficit normativo" de seu modelo de participação; do mesmo modo, chamam a atenção para as correções operadas por Honneth em sua resposta, dentre as quais se destacam a distinção entre reconhecimento verdadeiro e reconhecimento ideológico e a mudança de um padrão de reconhecimento identitário-intersubjetivo para outro referente à contribuição individual para a sociedade. $\mathrm{O}$ resultado, ao final do artigo, é uma contundente explicação da importância da análise social de fenômenos empíricos para a extração de uma dimensão normativa para a teoria do reconhecimento ou mesmo para uma teoria da justiça que se baseia nessa categoria, mas, ao mesmo tempo, uma crítica à ausência dessa mesma pesquisa empírica nos modelos discutidos, deixando em aberto a questão das experiências formativas, que é central na resposta de Honneth a Fraser. Todavia, se no artigo de Sobottka e de Santo já há indicaçóes de possíveis apropriaçóes e traduções dessas categorias para a realidade social brasileira, é dessas traduçóes, ainda de modo bastante geral, que tratam os textos daquilo que poderia ser visto como o segundo módulo do dossiê, e que foram escritos por Josué Pereira da Silva e Gustavo Cunha.

No artigo “'De que lado estás, Ariel?’: reconhecimento e redistribuição na teoria da emancipação de Boaventura de Sousa Santos”, Silva parte do comentário feito por Boaventura de Sousa Santos a respeito da relação entre 
redistribuição e reconhecimento e procura destrinchar o modelo epistemológico de uma teoria crítica do sul, desenvolvido pelo sociólogo português como um desdobramento da tradiçáo crítica de Marx e dos autores da Escola de Frankfurt, mas que visa superar seus elementos eurocêntricos e unilateralmente presos ao pressupostos conceituais da modernidade. Retomando a apropriação que Santos faz da obra de José Martí como uma oposição entre a "América europeia" e "Nuestra America", isto é, a América que se fundamenta em suas próprias raízes e não no pensamento de matriz europeia, Josué Pereira da Silva procede à exposição de um modelo normativamente contra-hegemônico de globalização. De acordo com Silva, é na construção desse paradigma contra-hegemônico que Santos enxerga a contribuição de sua teoria crítica para a teoria da emancipação: a criaçáo de constelaçóes de saberes contrapostas à logica mercantil globalizante que se erige sob a hegemonia dos Estados Unidos da América, a América europeia. É a partir desse ponto de vista, que de acordo com Silva, mescla diagnóstico de tempo e consideraçôes epistemológicas, que Santos irá teorizar a ascensão de mecanismos neoliberais nos quais o ideal de cidadania é esvaziado. Ao mesmo tempo, é aqui que se concentra sua discussão sobre os conceitos de redistribuição e reconhecimento, os quais, porém, são transformados nos conceitos de desigualdade e exclusão. Finalmente, tendo estabelecido a relação conceitual entre todas essas ideias, Silva realiza uma confrontação crítica dos propósitos teóricos de Boaventura de Sousa Santos, ressaltando, por um lado, seu comprometimento, típico de um intelectual orgânico gramsciano, muito mais profundamente anticapitalista do que Fraser ou Honneth, entretanto, por outro lado, apontando para problemas de excessivo esquematismo, falta de atenção a interlocutores centrais e certos descuidos categoriais da parte de Santos.

No texto seguinte, Gustavo Cunha realiza uma análise sobre os desdobramentos das obras de Fraser e Honneth após a publicação do livro conjunto de 2003. Para ele, os dois autores, mantendo em grande medida suas posiçôes antagônicas em relação ao debate entre reconhecimento e redistribuiçáo, vão procurar caracterizar o modo de funcionamento do capitalismo avançado nas sociedades contemporâneas e, assim, oferecer bases para o avanço das lutas sociais libertárias, na tradição da teoria crítica comum a ambos os autores. De todo modo, a evolução do pensamento 
fraseriano nos últimos 15 anos foi na direção de dar maior visibilidade à globalização e ao neoliberalismo, o que implicou uma maior proeminência ao conceito de participação paritária na sua teoria da justiça, a qual se torna cada vez mais marcada por uma vertente tripartite. E a obra posterior de Honneth também dará cada vez mais importância aos aspectos institucionais e normativos do reconhecimento, em que as injustiças deixam de ser vistas como interpessoais e mais como institucionais. Honneth, cada vez mais influenciado por autores como Durkheim e Dewey, verá, então, o reconhecimento menos pelo lado das lutas sociais que pelo dos critérios normativos que regulam a vida social.

Essas mudanças nas obras de Fraser e Honneth levam Cunha a se questionar sobre a pertinência do debate entre reconhecimento e redistribuição para a sociedade brasileira, tanto em termos conceituais para entender um país capitalista periférico, como o nosso, como em termos de apropriação desses conceitos pelos pesquisadores brasileiros. A partir de um instigante debate com o conceito das "ideias fora do lugar" de Roberto Schwarz, Cunha defende a ideia de que o debate entre reconhecimento e redistribuição continua a alimentar análises sociais perscrutadoras de tendências importantes da dinâmica capitalista no país.

Naquele que poderia ser visto como o próximo módulo temático do presente dossiê, há quatro textos que, partindo dos conceitos de redistribuição e reconhecimento, contribuem com análises nas quais algum aporte empírico é utilizado. O primeiro desses artigos é o texto de Patrícia Mattos, chamado "Desafios do reconhecimento nas relaçóes íntimas: um debate com Axel Honneth". A autora toma como seu ponto de partida a tentativa de Honneth de reformular sua concepçáo inicial a respeito da esfera do reconhecimento através do amor, um empreendimento que se deve, em grande medida, às críticas feitas por Fraser ao caráter excessivamente antropológico atribuído por ele àquele tipo de interação. A fim de investigar práticas sociais presentes nessa esfera do amor, Mattos apresenta os resultados de uma pesquisa realizada por meio de entrevistas temáticas sobre as vivências e expectativas do amor romântico. Nessa pesquisa, além disso, a autora ainda contribui com um tema um tanto quanto negligenciado na pesquisa em ciências sociais: o amor romântico heterossexual. Com esse movimento, ela mostra como, apesar da propensão à consideração da autorrealização mútua nas relações amorosas 
entre casais de classe média e média alta, o déficit de reconhecimento ainda é mais presente nas falas das mulheres. Com essa contribuição formulada a partir da pesquisa empírica, Mattos se posiciona criticamente a respeito da reconstrução normativa efetuada por Honneth a respeito do amor; para a autora, antes, é em trabalhos como o da socióloga franco-israelense Eva Illouz que as ambiguidades do amor vêm à tona com mais força, uma vez que ali o conceito central envolvido nas relaçóes interpessoais é o de autonomia, e não o de reconhecimento. É nesse sentido que Mattos se alia ao diagnóstico de Illouz e demonstra ambiguidades e tensóes no discurso do novo feminismo, que ela relaciona à tendência à institucionalização de uma ordem normativa ainda calcada nas representaçóes masculinas a respeito do amor.

A seguir, também em um texto que expóe resultados de uma pesquisa empírica, baseada em entrevistas em profundidade com tradutores no Brasil e na França, Cinara Rosenfield e Olivier Giraud tentam mostrar a fertilidade do conceito de autonomia desenvolvido por Honneth para entender a realidade do mundo do trabalho na contemporaneidade, a partir de um estudo de caso sobre o trabalho dos tradutores no Brasil e na França. De fato, para Honneth, a autonomia deve ser pensada em termos intersubjetivos e com uma dimensão social evidente, afastando-se, por isso, das definiçôes de autonomia assentadas em uma visão individualista. Dessa forma, a autonomia tem um caráter emancipatório fundamental e é a base para definir o que o autor conceitua como liberdade social, para além da liberdade individual. Nesse sentido, entender como se dá a busca por autonomia de um grupo de trabalhadores que sempre estiveram submetidos a normas trabalhistas marcadas pela ausência de vínculos institucionais estáveis com empresas, como são os tradutores, é uma forma de pensar o quanto esse conceito é útil para entender as formas de trabalho independente nas sociedades contemporâneas.

Para os autores do artigo, os dados empíricos arrolados indicariam que o trabalho independente sem algum tipo de regulação democrática pode se traduzir simplesmente na ausência de trabalho assalariado e de autonomia para os trabalhadores.

Já os últimos dois textos do dossiê se dedicam à análise da dimensão política do debate redistribuição e reconhecimento tomando como base 
a discussão acerca dos movimentos sociais e, mais precisamente, do movimento negro no Brasil. Assim, Paulo Sérgio da Costa Neves, no artigo intitulado "Reconhecimento ou redistribuição: o quê o debate entre Honneth e Fraser diz das lutas sociais e vice-versa", discute o movimento negro em Sergipe a partir do dilema da complementariedade ou não daqueles dois conceitos. Antes de chegar à análise do movimento social, então, $\mathrm{Ne}$ ves rememora tanto as origens do debate entre Fraser e Honneth quanto seus desdobramentos na obra de ambos, chamando atençáo para o caráter de "dupla hermenêutica" que, como ocorre nas ciências sociais de modo geral, faz dessa uma confrontação que, além de acadêmica é também política. Assumindo essa posição, o autor demonstra como as mudanças operadas por Fraser e Honneth em seus respectivos modelos significam correçóes efetuadas do ponto de vista da possibilidade de sua apropriação como aspectos da luta política por justiça social. Ao mesmo tempo em que reconhece a validade política do conceito de reconhecimento como status aplicada por Fraser, Neves adota uma posição avançada, por meio da qual, sem abrir mão da dimensão política associada ao status, ressalta a importância de que o status político a que se almeja tenha uma base concreta nos desejos de vida boa expressos pelos sujeitos, de modo que seria necessária uma mediação entre os modelos de Fraser e Honneth. É justamente esse tipo de ambiguidade dos discursos identitários sobre o reconhecimento e sua inclusão na esfera política do Estado que seus estudos no movimento negro sergipano revelaram. Ao final, informado por seus estudos desse movimento, o autor conclui que a dimensão política do debate contribui para a não reificação de categorias analíticas ao mesmo tempo em que coloca a pesquisadoras e atores sociais o desafio de navegarem nessas águas da teoria normativa e política da justiça.

O texto final do dossiê, de autoria de Angela Randolpho Paiva, busca dar inteligibilidade à emergência do moderno movimento negro no Brasil a partir de uma série de contribuiçôes teóricas. Questionando-se sobre a validade heurística de conceitos forjados inicialmente em países centrais para entender a realidade de países do Sul, a autora vai defender a ideia de que conceitos tais como cidadania, direitos humanos, autonomia do sujeito e reconhecimento são úteis para entendermos a história recente do Brasil e, em especial, o papel do movimento negro na emergência de 
demandas por direitos da população negra no país. Articulando contribuiçôes teóricas e metodológicas da sociologia dos movimentos sociais, da sociologia política e da teoria do reconhecimento, Paiva busca articular o processo de democratização do país com a emergência de novos sujeitos de direito. Desse modo, a autora revela que as demandas por reconhecimento articuladas pelo movimento negro são frutos de processos históricos que envolvem dimensóes variadas da saga democrática no país.

Com esse dossiê esperamos, portanto, contribuir para a difusão do debate entre redistribuição e reconhecimento, mas também com a pluralização das interpretaçôes feitas a partir desse debate a uma série de problemas sociológicos adicionais. Com o apoio dos editores, os organizadores agradecem às autoras e autores e desejam uma boa leitura.

\section{Referências}

DERANTY, J.-P. Beyond Communication. A Critical Study of Axel Honneth's Social Philosophy. Leiden; Boston: Brill, 2009.

FRASER, N. Justice Interrruptus: Critical Reflections on "Postsocialist" Condition. London; New York: Routledge, 1997.

FRASER, N. From progressive neoliberalism to Trump - and beyond. American Affairs, v. 1, n. 4, p. 46-64, winter 2017.

FRASER, N.; HONNETH, A. Redistribution or recognition? A political-philosophical exchange. London; New York: Verso, 2003.

HABERMAS, J; RAWLS, J. Débat sur la Justice Politique. Paris: Editions du CERF, 1997.

HONNETH, A. Kampf um Anerkennung. Zur moralischen Grammatik sozialer Konflikte. Frankfurt am Main: Suhrkamp, 1992.

HONNETH, A. Die soziale Dynamik von Mißachtung. Zur Ortbestimmung einer kritischen Gesellschaftstheorie. In: HONNETH, A. Das Andere der Gerechtigkeit. Aufsätze zur praktischen Philosophie. Frankfurt am Main: Suhrkamp, 2000. p.88-109

HONNETH, A. Luta por reconhecimento. A gramática moral dos conflitos sociais. Sáo Paulo: Editora 34, 2003.

JARDIM, C. R. P. O que as teorias do reconhecimento têm a dizer sobre as manifestações de rua em 2013 no Brasil. Sociedade e Estado, v. 31, p. 1071-1091, 2016.

KYMLICKA, W. Multicultural Citizenship: A Liberal Theory of Minority Rights. Oxford: Oxford University Press, 1995.

MACINTYRE, A. After Virtue: a Study in Moral Theory. Notre Dame: University of Notre Dame Press, 1981. 
MATTOS, P. C. A Sociologia Política do Reconhecimento: As contribuições de Charles Taylor, Axel Honneth e Nancy Fraser. São Paulo: Annablume, 2006.

MELO, R. S. A teoria crítica de Axel Honneth: Reconhecimento, liberdade e justiça. São Paulo: Saraiva, 2013.

NEVES, P. S. C. Luta anti-racista: entre reconhecimento e redistribuição. Revista Brasileira de Ciências Sociais, v. 20, n. 59, p. 81-96, out. 2005.

NEVES, P. S. C. Reconhecimento e desprezo social ou os dilemas da democracia no Brasil contemporâneo: algumas consideraçóes à luz da questáo racial. Política \& sociedade, v. 6, n. 11, p. 117-132, out. 2007.

OFFE, C. Trabalho: a categoria-chave da sociologia?. Revista Brasileira de Ciências Sociais, v. 10, n. 1, 1989.

PAIVA, A. R. Cidadania, reconhecimento e ação afirmativa no ensino superior. Civitas, v. 15, n. 4, p. 127-154, out./dez. 2015.

RAWLS, J. A theory of justice. Oxford: Clarendon Press, 1972.

ROEMER, J. Egalitarian Perspectives: Essays in Philosophical Economics. Cambridge: Cambrigde University Press, 1996.

ROSENFIELD, C. L.; SAAVEDRA, G. A. Reconhecimento, Teoria Crítica e Sociedade: sobre desenvolvimento da obra de Axel Honneth e os desafios da sua aplicação no Brasil. Sociologias, v. 33, p. 14-54, 2013.

ROSENFIELD, C. L.; MELLO, L. G.; CORRÊA, A. S. Reconstrução normativa em Axel Honneth e os múltiplos justos no mercado de trabalho. Civitas, v. 15, n. 4, p. 664-685, 2015.

SAAVEDRA, G. A.; SOBOTTKA, E. A. Discursos filosóficos do reconhecimento. Civitas, v. 9, n. 3, p. 386-401, set./dez. 2009.

SANDEL, M. Liberalism and the Limits of Justice. Cambridge; New York: Cambridge University Press. 1982.

SILVA, J. B. Racismo e sindicalismo - reconhecimento, redistribuição e ação política das centrais sindicais acerca do racismo no Brasil (1983-2002). São Paulo: Annablume, 2017.

SILVA, J. P. Trabalho, cidadania e reconhecimento. São Paulo: Annablume, 2008.

TAYLOR, C. Sources of the Self: The Making of the Modern Identity. Harvard: Harvard University Press, 1989.

TAYLOR, C. Multiculturalism and the "Politics of Recognition. Princeton: Princeton University Press, 1992.

YOUNG, I. M. Justice and the Politics of Difference. Princeton: Princeton University Press, 1990.

WALZER, M. Spheres of Justice: A Defense of Pluralism and Equality. New York: Basic Books, 1983. 